\title{
The Role of Ventromedial Prefrontal Cortex in the Recovery of Extinguished Fear
}

\author{
Gregory J. Quirk, Gregory K. Russo, Jill L. Barron, and Kelimer Lebron \\ Department of Physiology, Ponce School of Medicine, Ponce, Puerto Rico 00732
}

\begin{abstract}
Conditioned fear responses to a tone paired with footshock extinguish when the tone is presented repeatedly in the absence of shock. Rather than erase the tone-shock association, extinction is thought to involve new learning accompanied by inhibition of conditioned responding. Despite much interest in extinction from a clinical perspective, little is known about the neural circuits that are involved. Although the prefrontal cortex has a well established role in the inhibition of inappropriate behaviors, previous reports have disagreed as to the role of the ventromedial prefrontal cortex (vmPFC) in extinction. We have reexamined the effects of electrolytic vmPFC lesions made before training on the acquisition, extinction, and recovery of conditioned fear responses in a 2 d experiment. On Day 1 vmPFC lesions had no effect on acquisition or extinction of conditioned freezing and
\end{abstract}

suppression of bar pressing. On Day 2 sham rats recovered only $27 \%$ of their acquired freezing, whereas vmPFC-lesioned rats recovered $86 \%$, which was indistinguishable from a control group that never received extinction. The high recovery in lesioned rats could not be attributed to decreased motivation or altered sensitivity to footshock. vmPFC lesions that spared the caudal infralimbic (IL) nucleus had no effect. Thus, the vmPFC (particularly the IL nucleus) is not necessary for expression of extinction, but it is necessary for the recall of extinction learning after a long delay. These data suggest a role of the vmPFC in consolidation of extinction learning or the recall of contexts in which extinction took place.

Key words: extinction; infralimbic; prelimbic; fear conditioning; amygdala; inhibition
Prefrontal cortex has long been implicated in inhibition of inappropriate responses. Lesions of medial prefrontal cortex (mPFC) cause perseverative responding in animals and humans and cause deficits in reversal tasks (for review, see Kolb, 1984; Fuster, 1997). Perseverative responding in prefrontal animals was extended to conditioned fear when it was shown that rats with mPFC lesions could acquire freezing responses to a tone paired with a footshock, but they required many more days to extinguish those responses when the tone was presented alone (Morgan et al., 1993). More recent data support the hypothesis that mPFC is involved in the inhibition of fear responses (Bremner et al., 1999; Herry et al., 1999; Morrow et al., 1999), and it has been suggested that deficits in extinction of conditioned fear may cause certain anxiety disorders (Charney and Deutch, 1996; Pitman, 1997).

Many questions remain, however, concerning the role of the ventromedial prefrontal cortex (vmPFC) in extinction of fear. Following the original report by Morgan et al. (1993), Gewirtz et al. (1997) found no effect of vmPFC lesions on extinction of conditioned fear responses. To explain this discrepancy, Gewirtz et al. (1997) suggested that the prolonged extinction might have been attributable to increased acquisition in the lesioned animals, which was masked by asymptotic freezing levels. Another possible explanation for the discrepancy between the two studies concerns the extent to which the infralimbic nucleus (IL) was destroyed by the lesions. The IL contributes the majority of vmPFC inputs to the central nucleus of the amygdala (Sesack et al., 1989; Hurley et al., 1991), which plays a key role in the expression of behavioral and autonomic indices of conditioned fear (Kapp et al., 1979; LeDoux et al., 1988; Helmstetter, 1992; McCabe et al., 1992; Powell, 1994; Campeau and Davis, 1995; Maren, 1999; Amorapanth et al., 2000). IL also projects to

\footnotetext{
Received March 16, 2000; revised May 19, 2000; accepted May 23, 2000.

This work was supported by National Institutes of Health Grants R29-MH58883 and S06-GM08236 to G.J.Q. We thank Mohammed Milad for assistance with surgery and Justin A. Harris, Karim Nader, and Francisco Olucha for comments on an earlier draft of this manuscript.

Correspondence should be addressed to Dr. Gregory J. Quirk, Department of Physiology, Ponce School of Medicine, P.O. Box 7004, Ponce, Puerto Rico 00732-7004. E-mail: gjquirk@yahoo.com.

Copyright (C) 2000 Society for Neuroscience $0270-6474 / 00 / 206225-07 \$ 15.00 / 0$
}

many of the hypothalamic and midbrain sites that mediate fear responses (Sesack et al., 1989; Hurley et al., 1991).

We addressed these issues by comparing the effects of inclusive vmPFC lesions with IL-sparing rostral vmPFC lesions on the acquisition and extinction of conditioned fear responses. To maximize our chances of detecting potentiated acquisition in the lesioned group, we used a paradigm that produces a gradual acquisition curve with submaximal freezing. Previous studies have examined extinction over many days, with few extinction trials given per day. The ability of vmPFC rats to extinguish fear responses within a single session has not been examined. We conditioned and extinguished rats in a single day, and we tested for recovery of fear to the tone $24 \mathrm{hr}$ later. Two questions were asked. (1) Are vmPFC-lesioned rats able to express extinction from trialto-trial on Day 1? (2) Are vmPFC-lesioned rats able to recall extinction learning on Day 2? If the lesions prevented rats from inhibiting fear responses, deficits would be expected on both Days 1 and 2. Preserved extinction on Day 1 followed by recovery of fear on Day 2 would suggest a more complex role of vmPFC in extinction of fear.

An abstract containing some of these data has been published (Quirk et al., 1998).

\section{MATERIALS AND METHODS}

Subjects. All procedures were approved by the Institutional Animal Care and Use Committee (IACUC) of Ponce School of Medicine, in compliance with the Guide for the Care and Use of Laboratory Animals (Department of Health and Human Services publication 86-23). Male rats (Sprague Dawley) weighing $\sim 300 \mathrm{gm}$ were transferred from the Ponce School of Medicine colony to the laboratory, where they were housed individually in transparent polyethylene cages located in a negativepressure clean room (Colorado Clean Room, Ft. Collins, CO) and maintained on a $12 \mathrm{hr}$ light/dark schedule with free access to water. For $7 \mathrm{~d}$ the rats were handled daily and fed $10-15 \mathrm{gm} / \mathrm{d}$ of standard rat chow until they reached $85 \%$ of their original body weight. During this period they also were acclimated to the $45 \mathrm{mg}$ food pellets (Bioserve, Frenchtown, NJ) used for bar-press training.

Bar-press training. After handling, the rats were trained to press for food in a standard conditioning chamber, $25 \times 29 \times 28 \mathrm{~cm}$, with aluminum and Plexiglas walls (Coulbourn Instruments, Allentown, PA). The chamber included a shock floor with $0.5 \mathrm{~cm}$ diameter steel bars spaced at $1.8 \mathrm{~cm}$ and a response lever on one wall positioned $6.5 \mathrm{~cm}$ from the floor. A speaker was mounted to the outside of the opposite wall from the lever and faced a grating to permit sound to enter the chamber. The chamber was housed 
in a sound-attenuating box (Med Associates, Burlington, VT) to reduce ambient sound to $55 \mathrm{~dB}$. Pellet delivery was controlled by a computer running commercial behavioral testing software (Coulbourn Winlinc). Initially, rats received one pellet for each press. The reinforcement ratio was reduced gradually until rats learned to press $>20 / \mathrm{min}$ with a variableinterval schedule of reinforcement (VI-60). Bar-press training lasted $\sim 1$ week, after which rats were assigned to experimental and control groups on the basis of the output of a pseudo-random number generator (http:// www.randomizer.com). A small number of rats failing to press $>20 / \mathrm{min}$ were excluded from the study.

Surgery. After pretreatment with atropine sulfate $(0.27 \mathrm{mg} / \mathrm{kg}$, i.p. $)$, the rats were anesthetized with Nembutal (sodium pentobarbital, $60 \mathrm{mg} / \mathrm{kg}$, i.p.) and placed into a stereotaxic apparatus (David Kopf Instruments, Tujunga, CA). Supplemental doses of Nembutal $(5 \mathrm{mg})$ were given as needed to maintain a deep level of anesthesia, as indicated by a slow respiratory rate and lack of response to tail pinch. Body temperature was monitored with a rectal probe and maintained at $37-39^{\circ} \mathrm{C}$ with a heated gel pad. Surgical tools were sterilized with an antibacterial solution (Cidex) and rinsed in sterile water. The cranium was exposed and scraped, and a cautery was used to stop bleeding from the bone. After leveling the scalp so that lambda and bregma were in the same horizontal plane, we drilled burr holes bilaterally over the mPFC with a dental drill. A $125 \mu \mathrm{m}$ Teflon-insulated wire electrode with an $0.5 \mathrm{~mm}$ exposed tip (Rhodes Medical Instruments, Tujunga, CA) was lowered into the vmPFC, targeting the infralimbic nucleus. The coordinates relative to bregma were 2.7 $\mathrm{mm}$ anterior, $0.5 \mathrm{~mm}$ lateral, and $5.2 \mathrm{~mm}$ ventral (Paxinos and Watson, 1998). An electrolytic lesion was made by passing $1.0 \mathrm{~mA}$ of anodal current for $12 \mathrm{sec}$, using a DC stimulator with constant current output (GrassAstro Med, Warwick, RI). For sham-operated rats the electrode was lowered to a point just above the prelimbic cortex $(2.6 \mathrm{~mm}$ ventral to bregma), but no current was passed. The electrodes were removed and sterile bone wax was used to fill the burr hole. The skin was sutured with surgical thread, and antibiotic ointment was applied to prevent infection. Rats were given a single injection of buprenorphine hydrochloride (Buprenex, $0.02 \mathrm{mg} / \mathrm{kg}$, i.m.) to relieve postoperative pain and were allowed 1 week to recover.

Fear conditioning. During recovery from surgery the rats received an additional $1-3 \mathrm{~d}$ of bar-press training, after which fear conditioning commenced. The conditioned stimulus (CS) was a $4 \mathrm{kHz}$ pure tone lasting 30 sec, with a loudness of $80 \mathrm{~dB}$ SPL. The unconditioned stimulus (US) was a scrambled footshock delivered to the floor bars, with an intensity of 0.5 $\mathrm{mA}$ and duration of $0.5 \mathrm{sec}$ (tone and shock coterminating). The experiment took place over $3 \mathrm{~d}$. On experimental Day 0 the rats were allowed to bar press for $10 \mathrm{~min}$ in the conditioning chamber. No tones or shocks were given. The next day (Day 1) the rats were given five habituation trials (tone alone). This was followed immediately by seven conditioning trials (tones paired with shock). After a $1 \mathrm{hr}$ rest period in the home cage the rats were returned to the conditioning chamber for 15 extinction trials (tone alone) Day 1 training lasted $\sim 3$ hr. On Day 2 the rats received an additional 15 extinction trials, followed by two unsignaled footshocks $(0.5 \mathrm{~mA}, 0.5 \mathrm{sec})$ and 15 more extinction trials. Day 2 lasted $\sim 2 \mathrm{hr}$. During all phases of the experiment the intertrial interval varied at $\sim 4 \mathrm{~min}$, and food reward was continuously available on a VI-60 schedule. A computer controlled the delivery of shocks, tones, and food pellets. Between each session the floor trays and shock bars were removed and cleaned with a soapy sponge, and the chamber walls were wiped with a damp cloth.

There were four experimental groups. mPFC lesion and sham-operated rats were treated as above. Two additional control groups received a slightly different treatment. A "sham-unpaired" group received sham surgery and fear conditioning as described, except that the footshock and tone were unpaired explicitly during the conditioning phase. This served as a control of nonassociative effects of the stimuli. An "extinction-naïve" group received sham surgery and was conditioned identically to the lesion and sham groups. At $1 \mathrm{hr}$ after conditioning these rats were placed in the chamber and allowed to press for food, but no extinction tones were given. The amount of time spent in the chamber on Day 1 was identical for sham and extinction-naïve groups.

Conditioned fear responses to the tone were measured in two ways: percent freezing and suppression of bar pressing. The cumulative time spent freezing (absence of all movements except those related to respiration) was measured with a digital stopwatch either during the experiment or afterward from videotape. Observers measuring freezing were blind with respect to group assignment. For the suppression measure, bar presses were time-stamped, stored to disk, and analyzed off-line with an Excel spreadsheet programmed for this purpose. The rates of bar pressing during the $60 \mathrm{sec}$ that preceded each tone ("pretone") were compared with the rates during the $30 \mathrm{sec}$ tone ("tone"). As previously described, a suppression ratio was calculated (Bouton and Bolles, 1980; Armony et al., 1997):

$$
\text { Suppression Ratio }=\frac{\text { pretone }- \text { tone }}{\text { pretone }+ \text { tone }}
$$

The suppression ratio takes into account changes in baseline press rate in determining the effect of the tone on pressing. A value of 1 indicates complete suppression of bar pressing during the tone, whereas a value of 0 indicates no suppression whatsoever. During trials in which both pretone and tone were 0 , a value of 1 was used.
Sensitivity to footshock. After the completion of all extinction trials, lesion and sham groups were tested for sensitivity to footshock. Rats were placed into the conditioning chamber and given unsignaled footshocks of increasing amplitude. Starting with $0.05 \mathrm{~mA}$, footshock was increased in $0.05 \mathrm{~mA}$ increments until three response thresholds were reached: noticing (an orienting head movement), flinching (hind paws briefly raised off the bars), and vocalizing. An observer blind with respect to experimental group assignment measured thresholds.

Histology. After Day 2 the rats were given an overdose of Nembutal (100 $\mathrm{mg} / \mathrm{kg}$, i.p.) and perfused transcardially with physiological saline, followed by $10 \%$ buffered formalin. Brains were removed and post-fixed in $10 \%$ formalin with $30 \%$ sucrose. Subsequently, brains were paraffin-embedded and sectioned at $20 \mu \mathrm{m}$ on a microtome. Every third section was mounted on gelatin-coated slides and stained with cresyl violet to show Nissl bodies. Lesions were traced onto selected drawings from a stereotaxic atlas (Paxinos and Watson, 1998). Decisions to include or exclude animals on the basis of anatomical criteria were made without knowledge of the experimental results.

Data analysis. Freezing scores (in sec) and suppression ratios were compared with ANOVA (STATISTICA, Statsoft, Tulsa, OK). In most cases a two-way ANOVA with repeated measures was used. Following a significant omnibus $F$ ratio, all post hoc comparisons were performed by using Scheffé's method. In all figures the data are represented as means \pm SEM.

\section{RESULTS}

\section{Location of lesions}

Following previous studies (Morgan et al., 1993; Gewirtz et al., 1997), we targeted the ventral part of medial prefrontal cortex (vmPFC), which includes the ventral prelimbic cortex (PL, area 32) and the infralimbic cortex (IL, area 25). The border between the PL and IL is marked by the fusing of layers II and III in IL (Zilles and Wree, 1995). Previous studies have shown that damage to the dorsal mPFC (the anterior cingulate cortex, area 24) increases fear responses during both acquisition and extinction phases (Morgan and LeDoux, 1995). For this reason, animals with mPFC damage dorsal to the mid-prelimbic area (other than minor damage caused by electrode insertion) were discarded, leaving 17 rats with lesions restricted to vmPFC. Of these, 11 included $>70 \%$ destruction of IL at all levels, whereas six spared most or all of caudal IL. These groups were compared separately and will be referred to as vmPFC-inclusive (vmPFC-i) and vmPFC-rostral (vmPFC-r) groups (Fig. 1). A total of 29 sham-operated rats (with no damage to dorsal mPFC other than the electrode track) served as controls. Shams were divided into three groups: "sham" $(n=11)$, "shamunpaired" $(n=7)$, and "extinction-naïve" $(n=11)$. The total number of rats was 46.

\section{Acquisition and extinction of fear responses on Day 1}

Both freezing and suppression of bar pressing were used as indices of conditioned fear. Conditioned suppression (also known as the conditioned emotional response, CER; Estes and Skinner, 1941) offers the important advantage of maintaining a constant level of activity against which freezing to a discrete CS can be measured reliably. This is particularly important during long extinction sessions (in excess of $1 \mathrm{hr}$ ) to prevent rats from becoming drowsy or falling asleep.

Sham and lesion groups rapidly acquired conditioned freezing and suppression to the tone during the conditioning phase. Figure 2 shows freezing and suppression scores for each trial of the experiment (for simplicity, only sham and vmPFC-i groups are plotted). Conditioned responses increased gradually and did not reach a plateau. Figure 3 summarizes these data in blocks of trials for sham, vmPFC-i, and vmPFC-r groups. Peak freezing levels for the three groups (measured at the beginning of extinction) were 67 , 77 , and $56 \%$ of the tone, respectively. Peak suppression ratios were $0.85,0.95$, and 0.77 for sham, vmPFC-i, and vmPFC-r groups, respectively. One-way ANOVAs showed no significant difference between groups during acquisition (freezing: $F_{(2,25)}=0.62, p>$ 0.05 ; suppression: $\left.F_{(2,25)}=1.82, p>0.05\right)$. In contrast to the animals that received paired tones and shocks, the sham-unpaired group showed virtually no freezing to the tone throughout the entire experiment. The maximum freezing level for sham-unpaired animals in any trial was only $9 \%$. Thus, the high freezing values 
A

\section{vmPFC-inclusive}

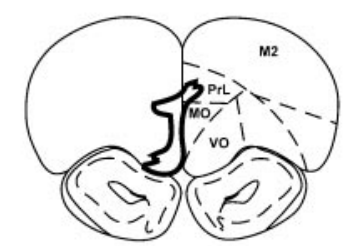

$+4.20$

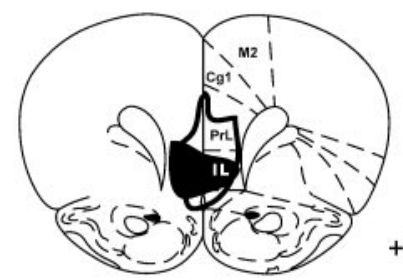

$+3.20$

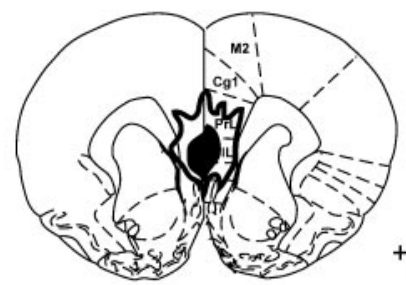

$+2.20$
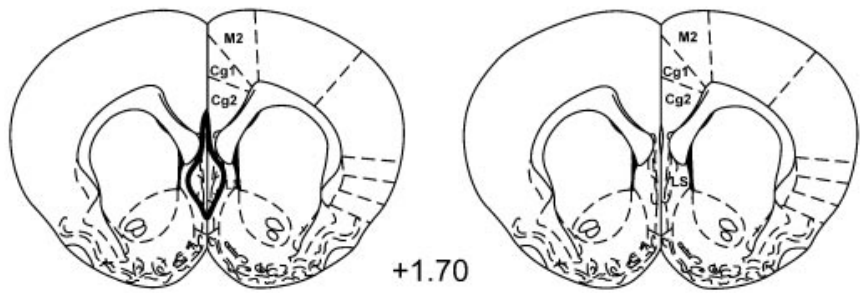

Figure 1. A diagram showing the extent of lesions in ventromedial prefrontal cortex (vmPFC). The largest (outline) and smallest (filled) lesions are shown for each level. $A$, The vmPFC-inclusive group showed $>70 \%$ destruction of the infralimbic nucleus at all levels $(n=11) . B$, The vmPFCrostral group spared some or all of the IL nucleus caudally $(n=6)$. Cg1, Anterior cingulate cortex; $D P$, dorsal peduncular nucleus; $I L$, infralimbic nucleus; $L S$, lateral septum; $M O$, medial orbital cortex; $M 2$, secondary motor cortex; PrL, prelimbic cortex; $V O$, ventral orbital cortex. Numbers indicate location anterior to bregma $(\mathrm{mm})$. Modified from Paxinos and Watson (1998).

observed in the lesion and sham groups were not attributable to sensitization effects.

At $1 \mathrm{hr}$ after conditioning the rats were given 15 extinction trials. Conditioned freezing and suppression responses rapidly extinguished in the lesion groups as well as in the shams (see Figs. 2, 3). At the conclusion of the extinction session, freezing and suppression values extinguished to preconditioning values. Two-way ANOVAs performed on the three phases of the experiment from Day 1 (habituation, early extinction, and late extinction) showed a significant main effect of phase (freezing: $F_{(2,50)}=197.1, p<0.001$; suppression: $\left.F_{(2,50)}=93.8, p<0.001\right)$, but no effect of group (freezing: $F_{(2,25)}=1.3, p>0.05$; suppression: $F_{(2,25)}=1.5, p>0.05$ ) or interaction between group and phase (freezing: $F_{(4,50)}=1.1, p>$ 0.05 ; suppression: $\left.F_{(4,50)}=0.9, p>0.05\right)$. Thus, all three groups acquired and extinguished equivalent amounts of conditioned freezing and suppression on Day 1. Post hoc comparisons showed no significant differences between the beginning and end of Day 1 (habituation vs late extinction) in either measure, suggesting that extinction on Day 1 was near complete.

\section{Recovery of conditioned fear responses on Day 2}

On Day 2 an additional 15 extinction trials were given to test for spontaneous recovery of fear responses to the tone. As shown in Figure 3, sham and vmPFC-r groups displayed relatively little
A
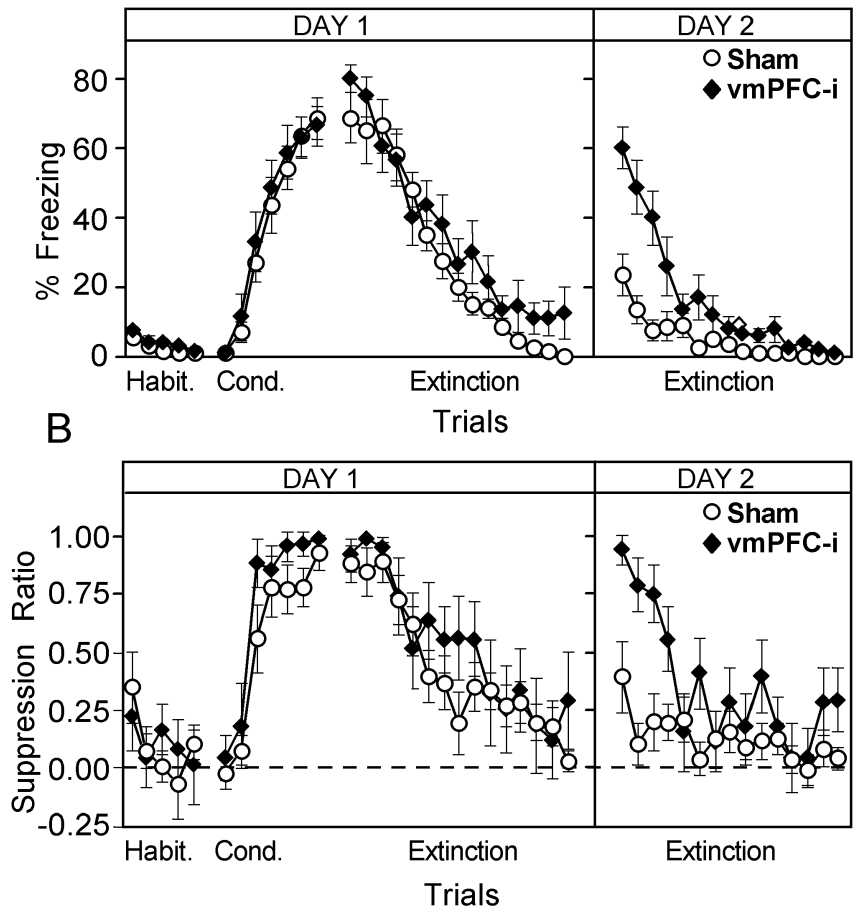

Figure 2. Average freezing $(A)$ and suppression $(B)$ values for each trial of the experiment. A habituation phase (tones alone) was followed by a conditioning phase (tones plus shocks) and an extinction phase (tones alone). Freezing is expressed as a percentage of the $30 \mathrm{sec}$ tone spent motionless. Suppression of bar pressing to the tone was expressed as a suppression ratio, which compared pretone rates with tone rates (see Materials and Methods). A ratio of 1.0 indicated maximal suppression to the tone, whereas 0 indicated no suppression. No difference in fear responses was found between the groups on Day 1. However, vmPFC-i animals showed higher recovery of the fear responses at the beginning of Day 2. Empty circle, Sham-operated; filled diamond, vmPFC-i lesion. In this and all subsequent figures the error bars indicate SEM.

freezing (sham, 18\%; vmPFC-r, 6\%) or suppression (sham, 0.24; vmPFC-r, 0.46) to the tone on Day 2. In contrast, the vmPFC-i animals showed pronounced freezing (54\%) and suppression (0.87) to the tone. A two-way ANOVA across Days 1 and 2 showed a significant main effect of group (freezing: $F_{(2,25)}=7.7, p<0.01$; suppression: $\left.F_{(2,25)}=7.5, p<0.01\right)$, and phase (freezing: $F_{(3,75)}=$ 138.1, $p<0.001$; suppression: $\left.F_{(3,75)}=69.9, p<0.001\right)$, as well as a significant interaction between group and phase (freezing: $F_{(6,75)}$ $=8.2, p<0.001$; suppression: $\left.F_{(6,75)}=3.9, p<0.001\right)$. Post hoc comparisons indicated that the experimental groups differed only on Day 2. For freezing on Day 2, the vmPFC-i group was significantly higher than either the sham $(p<0.001)$ or vmPFC-r $(p<$ $0.001)$ groups. For suppression, the vmPFC-i group was significantly higher than shams $(p<0.001)$, but not vmPFC-r rats $(p>$ $0.05)$. In both measures the vmPFC-i group's responses on Day 2 were not significantly different from the peak values acquired on Day 1, suggesting a high level of recovery in the vmPFC-i group.

The percentage of recovery of conditioned fear was calculated by dividing the freezing at the beginning of Day 2 (trials 1-2) by the conditioning phase on Day 1 (trials 6-7). Figure 4 shows the percentage of recovery for four groups: vmPFC-i, vmPFC-r, sham, and extinction-naïve. Extinction-naïve rats were sham-operated and conditioned, but they were not exposed to extinction tones on Day 1. As expected, extinction-naive rats recovered most of their acquired freezing to the tone $(89 \%)$ on Day 2 . In contrast, shams that were extinguished on Day 1 recovered only $27 \%$ of acquired freezing. vmPFC-i rats resembled extinction-naive controls, recovering $86 \%$, whereas vmPFC-r rats resembled shams, recovering only $20 \%$. Comparison of recovery with a one-way ANOVA indicated a highly significant effect of group $\left(F_{(3,35)}=11.5, p<0.001\right)$. 
A

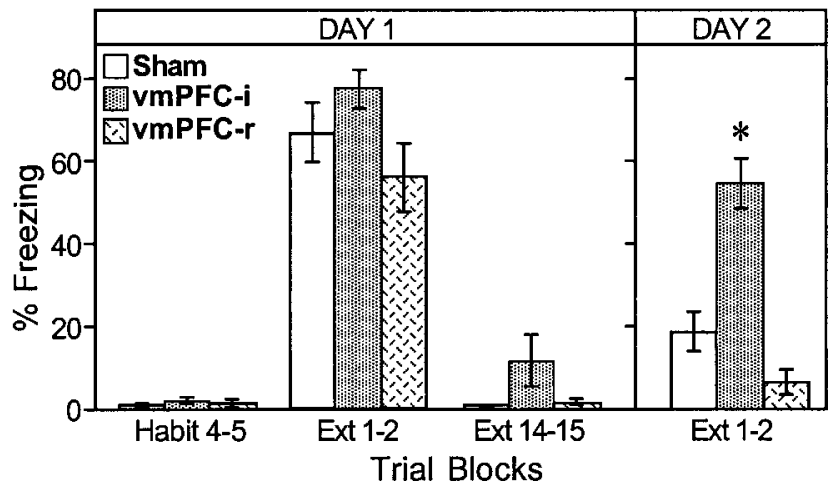

B

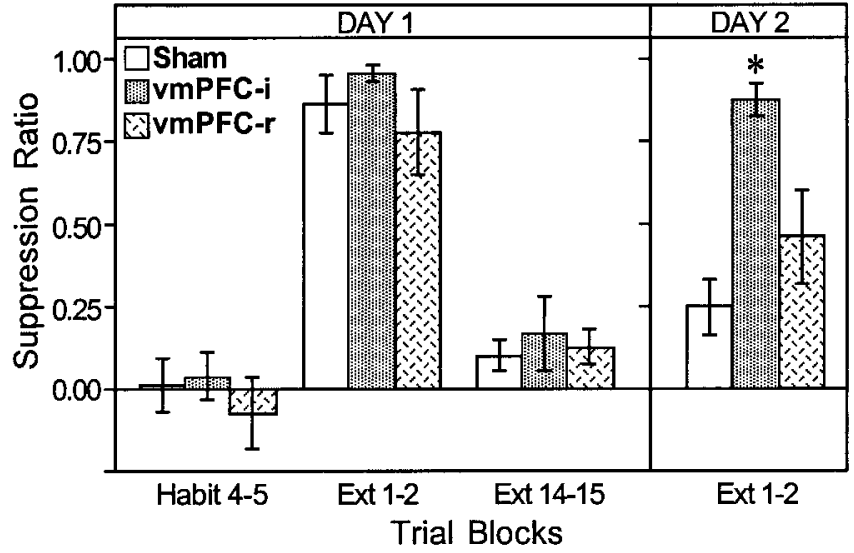

Figure 3. Average freezing $(A)$ and suppression $(B)$ values for two-tria blocks on Day 1 and Day 2 shown for sham-operated (empty bars), vmPFC-i ( filled bars), and vmPFC-r (hatched bars) groups. Note the high recovery of fear responses to the tone on Day 2 in the vmPFC-i group, but not in the vmPFC-r group. ANOVA indicated that the vmPFC-i group was significantly different from the sham group only on Day $2(p<0.001)$.
A

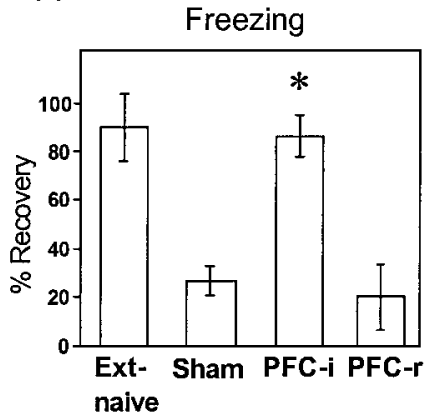

B

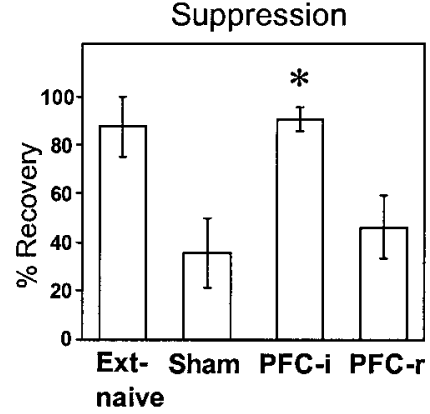

Figure 4. Recovery of extinguished freezing $(A)$ and suppression $(B)$ responses on Day 2, expressed as a percentage of fear response acquired on Day 1. Four groups are shown: extinction-naïve, sham-operated, vmPFC-i $(P F C-i)$, and vmPFC-r $(P F C-r)$. An asterisk indicates that the vmPFC-i group was significantly higher than the sham group $(p<0.001)$, but not significantly different from the extinction-naïve group $(p>0.05)$.

Post hoc tests confirmed the visual impressions of Figure $4 A$. vmPFC-i rats were significantly higher than shams $(p<0.01)$ and vmPFC-r $(p<0.01)$ rats, but not significantly different from the extinction-naive group $(p>0.05)$. The suppression values also showed a significant main effect of group $\left(F_{(3,35)}=6.0, p<0.001\right)$. vmPFC-i rats recovered significantly more suppression than shams $(p<0.05)$ but were not significantly higher than vmPFC-r rats $(p>0.05)$. The high recovery of fear responses in vmPFC-i rats
A
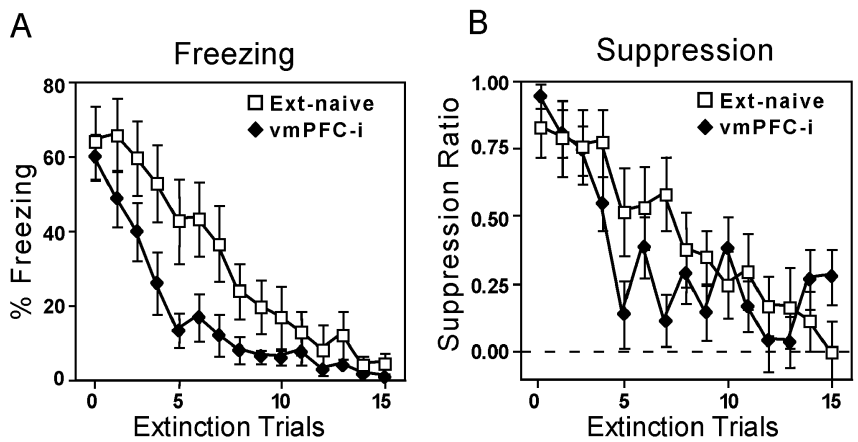

Figure 5. Extinction trials on Day 2 for vmPFC-i and extinction-naive groups, shown for freezing $(A)$ and suppression $(B)$. Despite complete recovery of fear responses on Day 2, vmPFC-i rats showed savings in their rate of extinction, suggesting some retention of extinction learning from Day 1.

was not attributable to any residual fear from the end of Day 1, because the difference between sham and vmPFC-i groups at the end of Day 1 was not significant (see above).

\section{Rate of extinction on Day 2}

There are two possible explanations for the high recovery of extinguished fear responses in vmPFC-i animals. (1) The extinction learning from Day 1 was never consolidated and therefore lost entirely, or (2) the extinction learning from Day 1 was consolidated but was inaccessible at the beginning of Day 2. One way of testing whether a memory is present but is not being expressed is to do a savings test. A comparison of extinction curves for Days 1 and 2 (see Fig. 2) shows that vmPFC-i rats extinguished more quickly on Day 2, suggesting savings. However, the extinction session on Day 2 occurred $24 \mathrm{hr}$ after conditioning, whereas the extinction session on Day 1 occurred only $1 \mathrm{hr}$ after conditioning. This difference could account for the lower fear observed on Day 2. We controlled for elapsed time after conditioning by comparing the extinction rate of vmPFC-i animals on Day 2 with the extinction-naïve group, also on Day 2. We reasoned that, if $v m P F C$-i rats were able to recall extinction, they should extinguish faster than rats that were being extinguished for the first time. Figure 5 shows that vmPFC-i rats in fact did extinguish more rapidly than extinction-naïve controls for both freezing and suppression. Thus, although lesioned rats showed full recovery of fear responses on Day 2, they retained some component of extinction training, as indicated by the rapid rate of extinction.

\section{Reinstatement of extinguished fear responses}

After 15 extinction trials on Day 2, the rats received two unsignaled shocks, followed ( 8 min later) by an additional 15 extinction trials. Previous studies have shown that unsignaled shocks can reinstate extinguished conditioned responses (Rescorla and Heth, 1975). The unsignaled shocks caused a moderate increase in freezing to the tone in sham (30\%), vmPFC-i (40\%), and vmPFC-r $(27 \%)$ groups, which rapidly extinguished. These data are shown in Figure $6 \mathrm{~A}$. A two-way ANOVA comparing preshock and postshock (trials $15-16)$ freezing values showed a main effect of trial $\left(F_{(1,25)}=39.4\right.$, $p<0.001)$ but no effect of group $\left(F_{(2,25)}=0.6, p>0.05\right)$, suggesting that the shocks increased all groups equivalently. To determine whether freezing was tone-specific or simply a continuation of pretone freezing, we subtracted pretone freezing from tone freezing in sham and sham-unpaired groups. This had little effect on sham freezing values, dropping them from 30 to $25 \%$ sec in trial 16. In contrast, unpaired rats dropped from 18 to $-0.4 \%$ sec (Fig. $6 B)$. An ANOVA on the difference values indicated a significant main effect of group $\left(F_{(1,13)}=6.2, p<0.05\right)$, a trend for main effect of trial $\left(F_{(1,13)}=4.4, p=0.055\right)$, and a significant interaction between trial and group $\left(F_{(1,13)}=6.0, p<0.05\right)$. Thus, the toneinduced freezing observed in sham-paired and vmPFC lesion groups that follows unsignaled shocks appears to be attributable to 
A

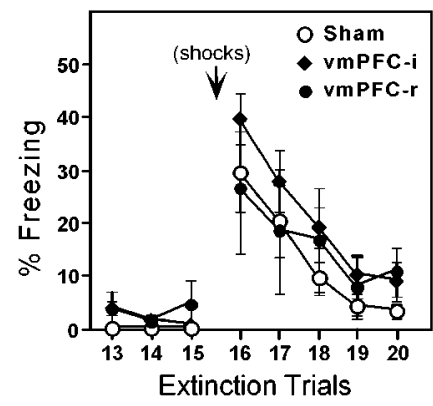

B

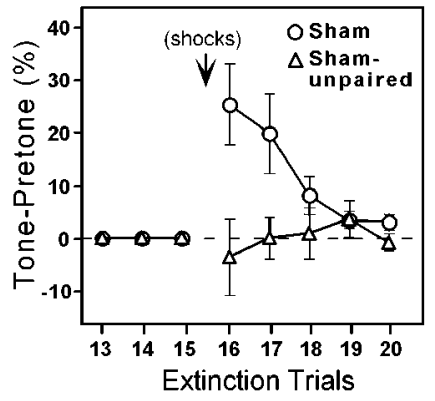

Figure 6. Reinstatement of freezing to the tone. $A$, Sham, vmPFC-i, and vmPFC-r groups increased their freezing to the tone after two unsignaled shocks. $B$, Freezing in the pretone period was subtracted from freezing during the tone for sham and sham-unpaired groups. Shams showed significant tone-induced freezing that was greater than pretone freezing, but sham-unpaired did not, indicating that increased freezing was not attributable to a sensitization effect.

A

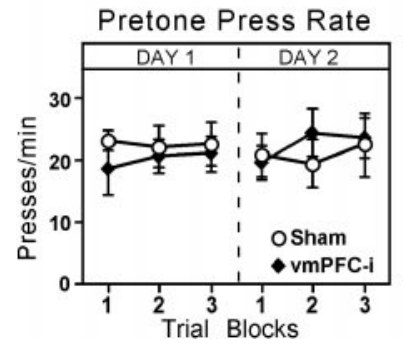

B

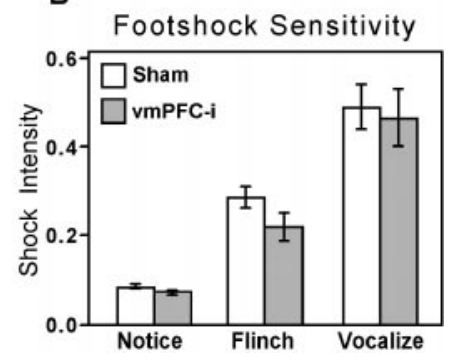

Figure 7. Pretone press rates and footshock sensitivity. $A$, Spontaneous press rates during the $60 \mathrm{sec}$ before tone onset for sham and vmPFCgroups. Blocks of five trials during the extinction sessions of Day 1 and Day 2 are shown. Press rates did not differ between groups or across trials. $B$, Footshock response thresholds for sham and vmPFC-i groups. vmPFC-i lesions did not alter sensitivity to footshock.

reinstatement of a previously conditioned association rather than a sensitization effect, because sham-unpaired rats showed no increase. Lesioning vmPFC did not interfere with this reinstatement process.

\section{Footshock sensitivity and activity controls}

Despite the large effect of vmPFC-i lesions on the recovery of fear responses on Day 2, there was no effect of the lesions on spontaneous press rates. Figure $7 A$ shows the average pretone press rates for sham and vmPFC-i groups on Days 1 and 2. Shams and lesioned rats pressed at $\sim 20 /$ min throughout. There were no significant differences between groups or between blocks of trials. In other words, pretone press rates were constant during periods when fear to the tone changed dramatically. Two conclusions can be drawn. First, lesions of vmPFC-i did not produce a general deficit in bar pressing nor a reduction in motivation to press for food. Second, pretone press rates revealed no evidence of context conditioning in either group. For example, at the beginning of extinction on Day 1, when pressing during the tone was most suppressed in both groups, pretone rates were unchanged.

At the conclusion of the experiment, sham and vmPFC-i groups were tested for footshock response thresholds. Three behaviors were assessed: notice, flinch, and vocalize (Fig. 7B). A two-way ANOVA showed a significant main effect of behavioral response $\left(F_{(2,28)}=66, p<0.0001\right)$, but no effect of $\operatorname{group}\left(F_{(2,28)}=0.58, p>\right.$ $0.05)^{28)}$. Thus, the increased recovery of fear in vmPFC-i rats cannot be attributed to an increase in sensitivity to footshock because vmPFC-i lesions did not alter response thresholds significantly.

\section{DISCUSSION}

We have examined the effects of electrolytic lesions of vmPFC on the acquisition, extinction, and recovery of conditioned fear, fol-

lowing earlier conflicting reports (Morgan et al., 1993; Gewirtz et al., 1997). Animals without vmPFC acquired normal levels of freezing and suppression in response to a tone that was paired with footshock. Furthermore, vmPFC-lesioned animals extinguished their fear responses to the tone when it was presented without the shock, in an extinction session. However, $24 \mathrm{hr}$ later the rats with vmPFC lesions that included most of the infralimbic nucleus (vmPFC-i) recovered most of the acquired freezing and suppression. In contrast, sham-operated rats recovered little conditioned fear. Rats with lesions of vmPFC that spared IL (vmPFC-r) were similar to shams. Finally, both lesion groups showed normal reinstatement of extinguished fear to the tone that followed unsignaled shocks.

Gewirtz and colleagues (1997) attempted to explain the discrepancy between their negative findings and those of Morgan et al. (1993) by suggesting that vmPFC lesions increased acquisition, thereby prolonging extinction. In fact, lesions of the dorsal mPFC have just this effect (Morgan and LeDoux, 1995). Increased acquisition of freezing in vmPFC-lesioned rats was not reported by Morgan et al. (1993), but it could have been missed because of the asymptotic freezing levels in that study. This is not a problem in the present study because we used a paradigm that (1) produced a gradual acquisition curve in which potentiated acquisition could be detected and (2) produced submaximal freezing. Under these conditions the vmPFC-lesioned rats did not acquire significantly more conditioned freezing than controls did. We therefore believe it is unlikely that extinction-related deficits in vmPFC rats are attributable to increased levels of acquisition. Although acquisition appeared normal in lesioned rats, we cannot rule out the possibility that animals without vmPFC acquire CS-US associations in a manner different from intact animals.

Preserved acquisition of conditioned fear in animals with damage to $\mathrm{vmPFC}$ agrees with previous findings for conditioned freezing (Morgan et al., 1993; Morrow et al., 1999), blood pressure changes (Fryztak and Neafsey, 1994), eyeblink responses (Buchanan and Powell, 1982; Chachich and Powell, 1998), and skin conductance changes (Bechara et al., 1999). Powell and colleagues have shown that $\mathrm{mPFC}$ lesions block heart rate conditioning in rabbits (Buchanan and Powell, 1982; Powell, 1994), but ventral mPFC lesions similar to ours had no effect (Powell et al., 1994).

We observed that vmPFC animals exhibited normal extinction of conditioned fear responses during the extinction session on Day 1. Thus, the expression of extinction, which depends on GABAergic systems (Harris and Westbrook, 1998), is normal in vmPFC-lesioned rats. This argues against the simple hypothesis that $\mathrm{mPFC}$ is the structure responsible for inhibiting fear responses during an extinction session. A recent study confirms that vmPFC damage does not prevent within-session extinction of conditioned skin conductance responses in humans (Bechara et al., 1999). These findings suggest that vmPFC does not perform a working memory function during extinction, because retention of nonreinforcement is normal from trial to trial. A different conclusion was reached by Morrow and colleagues, who recently demonstrated that 6-hydroxydopamine (6OHDA) lesions of vmPFC prevented within-session extinction of conditioned freezing (Morrow et al., 1999). This effect was dependent on footshock intensity and was observed with $0.8 \mathrm{~mA}$, but not $0.4 \mathrm{~mA}$ (a value closer to the present study). The recruitment of catecholamine systems during stress (Bremner et al., 1996) may play a greater role in extremely aversive rather than mildly aversive associations. Interestingly, locus coeruleus lesions that depleted frontal cortex of norepinephrine interfered with extinction between sessions, but not within a session, in a conditioned eyeblink paradigm (McCormick and Thompson, 1982).

Despite full extinction of conditioned fear responses on Day 1, vmPFC-i-lesioned rats recovered the same amount of freezing on Day 2 as extinction-naïve rats. The difference between vmPFC-i and sham groups cannot be attributed to food deprivation or the use of the CER. Lesioned rats were motivated equally to press for food, as indicated by similar pretone press rates in vmPFC-i and sham rats. Food deprivation by itself does not affect conditioned 
freezing (Maren and Fanselow, 1998). The recovery of extinguished fear we observed could slow extinction rates in animals tested over many days (Morgan et al., 1993). Thus, vmPFC may be required for consolidation of extinction learning such that damage to vmPFC would prevent long-term, but not short-term, memory for extinction.

An alternative possibility concerns the role of context. Although conditioned fear associations to a tone CS are in large part independent of context, extinction is context-dependent. Accordingly, extinguished fear responses are "renewed" when rats are placed in a chamber different from the one in which extinction occurred (Bouton and King, 1983). It has been proposed that context determines the meaning of a conditioned stimulus that has been made ambiguous by an extinction experience (Bouton, 1994). This suggests that the CS is linked to the context during extinction (Harris et al., 2000). The recovery of extinguished fear responses we observed is similar to the renewal phenomenon and suggests that vmPFC may be necessary for recalling a context in which extinction occurred.

It is difficult with the present data to distinguish between consolidation and contextual functions for vmPFC in extinction. We observed normal reinstatement of extinguished fear with unsignaled shocks, which is also context-dependent (Bouton and King, 1983). In their original report Morgan et al. (1993) found no effect of vmPFC lesions on extinction of contextual freezing. However, the savings we observed on Day 2 suggest that consolidation of extinction did occur to some extent in lesioned rats. Additional experiments are needed to determine whether varying temporal or contextual parameters could induce lesioned rats to recall extinction learning on Day 2. In addition, multichannel recordings from vmPFC neurons, similar to previous analyses of amygdala and auditory cortex (Quirk et al., 1995, 1997), are currently underway that will determine the features of extinction training signaled by vmPFC neurons.

Our findings suggest a high degree of anatomical specificity in the control of spontaneous recovery by prefrontal cortex. Although complete lesions of vmPFC (prelimbic and infralimbic cortices) caused recovery of fear, lesions that spared the caudal IL had no effect. This could account for the negative findings of Gewirtz and colleagues, who spared the caudal IL in a proportion of their animals [Gewirtz et al. (1997), their Fig. 1]. Whereas the mPFC projects to both the basolateral and central nuclei of the amygdala (McDonald, 1998), projections to the central nucleus (Ce) arise exclusively from IL (Hurley et al., 1991; Takagishi and Chiba, 1991; Buchanan et al., 1994). In fact, IL projections to Ce are strongest from its caudal part (Room et al., 1985; McDonald et al., 1996). The central nucleus of the amygdala mediates conditioned freezing, autonomic changes, and potentiated startle via its projections to periaqueductal gray (PAG), lateral hypothalamus, and caudal pontine reticular formation, respectively (Davis, 1994; Fendt and Fanselow, 1999; LeDoux, 2000). IL projections to Ce could influence all of these conditioned responses to extinguished stimuli. Alternatively, direct projections from the IL to the PAG and hypothalamus (Hurley et al., 1991; Takagishi and Chiba, 1991) might modulate fear responses independently of the amygdala. Although both circuits are plausible, the amygdala seems to play a key role because blockade of NMDA receptors in the amygdala prevents extinction (Falls et al., 1992). Also, whereas lesions of Ce prevent the acquisition of both conditioned suppression (Thompson and Schwartzbaum, 1964; Killcross et al., 1997) and conditioned freezing, recent data suggest that lesions of PAG block freezing but leave conditioned suppression intact (Amorapanth et al., 1999). We observed effects of vmPFC lesions on both behaviors, consistent with vmPFC modulation of a structure upstream from PAG, such as Ce.

In conclusion, we have shown that rats with lesions of ventral $\mathrm{mPFC}$ are able to acquire and extinguish conditioned fear, but they recover extinguished fear when tested $24 \mathrm{hr}$ later. These findings extend previous studies (Morgan et al., 1993; Herry et al., 1999; Morrow et al., 1999) by showing that vmPFC is necessary for recalling a previously learned extinction experience, rather than learning extinction per se. Recovery of extinguished fear is a common feature of anxiety disorders such as post-traumatic stress disorder (PTSD). Recent functional imaging studies have shown abnormally low activity in the ventromedial prefrontal cortex of PTSD patients who are reexposed to trigger stimuli (Shin et al., 1997; Bremner et al., 1999). Further study of the vmPFC and its targets in the amygdala and elsewhere may hold the key to understanding how the brain keeps conditioned fear associations in check.

\section{REFERENCES}

Amorapanth P, Nader K, LeDoux JE (1999) Lesions of the periaqueductal gray dissociate-conditioned freezing from conditioned suppression behavior in rats. Learn Mem 6:491-499.

Amorapanth P, LeDoux JE, Nader K (2000) Different lateral amygdala outputs mediate reactions and actions elicited by a fear-arousing stimulus. Nat Neurosci 3:74-79.

Armony JL, Servan-Schreiber D, Romanski LM, Cohen JD, LeDoux JE (1997) Stimulus generalization of fear responses: effects of auditory cortex lesions in a computational model and in rats. Cereb Cortex 7:157-165

Bechara A, Damasio H, Damasio AR, Lee GP (1999) Different contributions of the amygdala and ventromedial prefrontal cortex to decisionmaking. J Neurosci 19:5473-5481.

Bouton ME (1994) Context, ambiguity, and classical conditioning. Curr Dir Psychol Sci 3:49-53.

Bouton ME, Bolles RC (1980) Conditioned fear assessed by freezing and by the suppression of three different baselines. Anim Learn Behav 8:429-434.

Bouton ME, King DA (1983) Contextual control of the extinction of conditioned fear: tests for the associative value of the context. J Exp Psychol Anim Behav Process 9:248-265.

Bremner JD, Krystal JH, Southwick SM, Charney DS (1996) Noradrenergic mechanisms in stress and anxiety. I. Preclinical studies. Synapse 23:28-38.

Bremner JD, Staib LH, Kaloupek D, Southwick SM, Soufer R, Charney DS (1999) Neural correlates of exposure to traumatic pictures and sound in Vietnam combat veterans with and without post-traumatic stress disorder: a positron emission tomography study. Biol Psychiatry 45:806-816.

Buchanan SL, Powell DA (1982) Cingulate cortex: its role in Pavlovian conditioning. J Comp Physiol Psychol 96:755-774.

Buchanan SL, Thompson RH, Maxwell BL, Powell DA (1994) Efferent connections of the medial prefrontal cortex in the rabbit. Exp Brain Res 100:469-483.

Campeau S, Davis M (1995) Involvement of the central nucleus and basolateral complex of the amygdala in fear conditioning measured with fear-potentiated startle in rats trained concurrently with auditory and visual conditioned stimuli. J Neurosci 15:2301-2311.

Chachich M, Powell DA (1998) Both medial prefrontal and amygdala central nucleus lesions abolish heart rate classical conditioning, but only prefrontal lesions impair reversal of eyeblink differential conditioning. Neurosci Lett 257:151-154.

Charney DS, Deutch A (1996) A functional neuroanatomy of anxiety and fear: implications for the pathophysiology and treatment of anxiety disorders. Crit Rev Neurobiol 10:419-446.

Davis M (1994) The role of the amygdala in emotional learning. Int Rev Neurobiol 36:225-266.

Estes WK, Skinner BF (1941) Some quantitative properties of anxiety. J Exp Psychol 29:390-400.

Falls WA, Miserendino MJD, Davis M (1992) Extinction of fearpotentiated startle: blockade by infusion of an NMDA antagonist into the amygdala. J Neurosci 12:854-863.

Fendt M, Fanselow M (1999) The neuroanatomical and neurochemical basis of conditioned fear. Neurosci Biobehav Rev 23:743-760.

Fryztak RJ, Neafsey EJ (1994) The effect of medial frontal cortex lesions on cardiovascular conditioned emotional responses in the rat. Brain Res 643:181-193.

Fuster JM (1997) The prefrontal cortex. Philadelphia: Lippincott.

Gewirtz JC, Falls WA, Davis M (1997) Normal conditioned inhibition and extinction of freezing and fear-potentiated startle following electrolytic lesions of medial prefrontal cortex in rats. Behav Neurosci 111:712-726.

Harris JA, Westbrook RF (1998) Evidence that GABA transmission mediates context-specific extinction of learned fear. Psychopharmacology (Berl) 140:105-115.

Harris JA, Jones ML, Bailey GK, Westbrook RF (2000) Contextual control over conditioned responding in an extinction paradigm. J Exp Psychol Anim Behav Process 26:174-185.

Helmstetter F (1992) The amygdala is essential for expression of conditioned hypoalgesia. Behav Neurosci 106:518-528.

Herry C, Vouimba R, Garcia R (1999) Plasticity in the mediodorsal thalamo-prefrontal cortical transmission in behaving mice. J Neurophysiol 82:2827-2832.

Hurley KM, Herbert H, Moga MM, Saper CB (1991) Efferent projections of the infralimbic cortex of the rat. J Comp Neurol 308:249-276. 
Kapp BS, Frysinger RC, Gallagher M, Haselton JR (1979) Amygdala central nucleus lesions: effects on heart rate conditioning in the rabbit. Physiol Behav 23:1109-1117.

Killcross S, Robbins TW, Everitt BJ (1997) Different types of fearconditioned behavior mediated by separate nuclei within the amygdala. Nature 388:377-380.

Kolb B (1984) Functions of the frontal cortex of the rat: a comparative review. Brain Res Rev 8:65-98.

LeDoux JE (2000) Emotion circuits in the brain. Annu Rev Neurosci 23:155-184.

LeDoux JE, Iwata J, Cicchetti P, Reis DJ (1988) Different projections of the central amygdaloid nucleus mediate autonomic and behavioral correlates of conditioned fear. J Neurosci 8:2517-2529.

Maren S (1999) Neurotoxic basolateral lesions impair learning and memory but not performance of conditioned fear in rats. J Neurosci 19:8696-8703.

Maren S, Fanselow MS (1998) Appetitive motivational states differ in their ability to augment aversive fear conditioning in rats (Rattus norvegicus). J Exp Psychol Anim Behav Process 24:369-373.

McCabe PM, Schneiderman N, Jarrell TW, Gentile CG, Teich AH, Winters RW, Liskowsky DR (1992) Central pathways involved in differential classical conditioning of heart rate responses. In: Learning and Memory: the behavioral and biological substrates (Gormezano I, Wasserman EA, eds), pp 321-346. Hillsdale, NJ: Erlbaum.

McCormick DA, Thompson RF (1982) Locus coeruleus lesions and resistance to extinction of a classically conditioned response: involvement of the neocortex and hippocampus. Brain Res 245:239-249.

McDonald AJ (1998) Cortical pathways to the mammalian amygdala. Prog Neurobiol 55:257-332.

McDonald AJ, Mascagni F, Guo L (1996) Projections of the medial and lateral prefrontal cortices to the amygdala: a Phaseolus vulgaris leucoagglutinin study in the rat. Neuroscience 71:55-75.

Morgan MA, LeDoux JE (1995) Differential contribution of dorsal and ventral medial prefrontal cortex to the acquisition and extinction of conditioned fear in rats. Behav Neurosci 109:681-688

Morgan MA, Romanski LM, LeDoux JE (1993) Extinction of emotional learning: contribution of medial prefrontal cortex. Neurosci Lett 163:109-113.

Morrow BA, Elsworth JD, Rasmusson AM, Roth RH (1999) The role of mesoprefrontal neurons in the acquisition and expression of conditioned fear in the rat. Neuroscience 92:553-564.

Paxinos G, Watson C (1998) The rat brain in stereotaxic coordinates. San Diego: Academic.
Pitman RK (1997) Overview of biological themes in PTSD. Ann NY Acad Sci 821:1-9.

Powell DA (1994) Rapid associative learning: conditioned bradycardia and its central nervous system substrates. Integr Physiol Behav Sci 29:109-133.

Powell DA, Watson K, Maxwell B (1994) Involvement of subdivisions of the medial prefrontal cortex in learned cardiac adjustments in rabbits. Behav Neurosci 108:294-307.

Quirk GJ, Repa JC, LeDoux JE (1995) Fear conditioning enhances short latency auditory responses of neurons in the lateral nucleus of the amygdala: parallel recordings in the freely behaving rat. Neuron 15:1029-1039.

Quirk GJ, Armony JL, LeDoux JE (1997) Fear conditioning enhances different temporal components of tone-evoked spike trains in auditory cortex and lateral amygdala. Neuron 19:613-624.

Quirk GJ, Kohanski GJ, Ayala O (1998) Lesions of medial prefrontal cortex retard extinction of fear conditioning between sessions, but not within a session. Soc Neurosci Abstr 24:1683.

Rescorla RA, Heth CD (1975) Reinstatement of fear to an extinguished conditioned stimulus. J Exp Psychol Anim Behav Process 1:88-96.

Room P, Russchen FT, Groenewegen HJ, Lohman A (1985) Efferent connections of the prelimbic (area 32) and the infralimbic (area 25) cortices: an anterograde tracing study in the cat. J Comp Neurol 242:40-55.

Sesack SR, Deutch AY, Roth RH, Bunney BS (1989) Topographical organization of the efferent projections of the medial prefrontal cortex in the rat: an anterograde tract-tracing study with Phaseolus vulgaris leucoagglutinin. J Comp Neurol 290:213-242.

Shin LM, Kosslyn SM, McNally RJ, Alpert NM, Thompson WL, Rauch SL, Macklin ML, Pitman RK (1997) Visual imagery and perception in post-traumatic stress disorder. A positron emission tomographic investigation. Arch Gen Psychiatry 54:233-241.

Takagishi M, Chiba T (1991) Efferent projections of the infralimbic (area $25)$ region of the medial prefrontal cortex in the rat: an anterograde tracer PHA-L study. Brain Res 566:26-39.

Thompson JB, Schwartzbaum JS (1964) Discrimination behavior and conditioned suppression (CER) following localized lesions of the amygdala and putamen. Psychol Rep 15:587-606.

Zilles K, Wree A (1995) Cortex: areal and laminar structure. In: The rat nervous system, 2nd Ed (Paxinos G, ed), pp 649-685. San Diego: Academic. 